\title{
Sistema Produto - Serviço: Uma análise de aplicação da gestão de design em um caso de servitização em produtos do vestuário
}

\author{
Product-Service System: Ananalysisoftheapplicationof design management in \\ a case ofservitization in clothingproducts
}

\begin{abstract}
ALANO, Agda Bernardete - Mestranda em Gestão de Design
Universidade Federal de Santa Catarina - UFSC

agda.alano@gmail.com
\end{abstract}

\section{FIGUEIREDO Fernando Luiz - Doutor em Engenharia}

Universidade Federal de Santa Catarina - UFSC

Iff@cce.ufsc.br

\section{MERINO, Giselle Gisel Schmidt Alves Diaz - Mestre em Gestão de Design}

Universidade Federal de Santa Catarina - UFSC

gisellemerino@gmail.com

\begin{abstract}
Resumo
O sistema de produto-serviço tem sido tratado pela gestão de design a partir de modelos em PSS que se caracteriza como soluções completas e integradas de bens e serviços. Ações sustentáveis podem ser identificadas a partir do reprocessamento de produtos, prolongando o seu tempo de vida evitando o descarte prematuro e a geração de resíduos. Este estudo relaciona uma empresa que recondiciona produtos do vestuário a modelos de PSS a fim de identificar por meio da gestão de design ações sustentáveis, bem como propor ações futuras com a aplicação do design de moda ao recondicionamento de produto de vestuário como forma de renovação dos valores estéticos e simbólicos.
\end{abstract}

Palavras-chave: Design de moda. Vestuário infantil. Vestuário com conceitos de aprendizagem.

\section{Abstract}

Garments with innovative features, such as those that generates knowledge by elements inserted into the pieces, is a trend in the market directed to the children's segment. Thus, this study seeks to guide the design of children's clothing that aim to learning, combining design concepts. For this, a survey was conducted of the theoretical issues that surround this topic and as a result is presented a set of recommendations for the production of this type of clothing.

Keywords: Fashion design. Children's Clothing. Clothing with learning concepts. 


\section{INTRODUC̣̃̃O}

O sistema de produto serviço tem sido tratado pela gestão de design a partir de modelos em PSS (em inglês) "Product/Service System" que se caracteriza como soluções completas e integradas de bens e serviços.

Segundo Borchard, Sellitto e Pereira (2010), PSS teve sua origem na sustentabilidade ambiental, a partir do uso intensivo dos produtos, oferecendo soluções de forma a garantir uma maximização dos recursos físicos e assim resultando em um maior aproveitamento de recursos. Este fato representa uma maior margem de lucro para empresa, porém o que se destaca neste estudo é o aproveitamento de recursos como benefício também para o usuário, sendo analisado a partir das soluções oferecidas pelo serviço de recondicionamento de roupas.

Empresas que trabalham nesta segmentação oferecem soluções a um público que não pretende descartar ou deixar em desuso uma determinada roupa renovando-a a partir de técnicas que seriam utilizadas de forma doméstica como: a costura, tingimento e a lavagem. Este tipo de serviço pode indicar uma característica de um modelo em PSS, porém para que se faça tal associação é necessária que se conheça sobre modelos de servitização, e em especial neste estudo, sua relação com a sustentabilidade.

Este estudo apresenta uma contextualização de PSS, a partir de uma breve definição conceitual e histórica, e relaciona categorias definidas segundo autores como Azarenko et al. (2009), Rese et, Strotmann e Karger (2009), Yang et al. (2009) e Tukker (2004).

Em seguida relaciona o Design e a sustentabilidade com base no consumo e neste sentido é levado em conta o processo (produção de bens-serviços); assim como na perspectiva do usuário, são apresentados aspectos de uma pesquisa realizada por Laitala e Boks (2012) sobre o comportamento do consumidor na fase de uso do vestuário com relação à sustentabilidade.

Com base na contextualização sobre PSS e os dados coletados da empresa, o estudo apresenta uma categorização da empresa, relacionando-a a um modelo de PSS, utilizando-se de uma abordagem sistêmica para a identificação de suas estruturas e relações.

Por último o estudo apresenta à aplicação da pesquisa na empresa com base em uma coleta de dados documentais e por meio de entrevistas semiestruturadas aplicadas aos envolvidos com a gestão da organização. Assim foi possível apresentar diagramas capazes de relacionar a práticas já 
adotadas na empresa e sua relação com o PSS, bem como prospectar ações futuras possíveis de serem implementadas por ações de design considerando no sistema produto-serviço à sustentabilidade como valor.

\section{Contextualização do Product-Service System (PSS)}

O conceito de PSS teve sua origem, nos anos 1990, no norte da Europa.

Iniciou com uma abordagem focada na ecologia industrial, centrada no conceito de "vender performance" em vez de vender "bens" (SPRING; ARAÚJO, 2009). PSS é um caso de servitização e pode ser concebido como uma extensão da operacionalidade de um bem físico, agregando serviços especializados. "[...] O que é vendido é o direito de uso do bem, não o direito de propriedade"(BORCHARDT, SELLITTO; PEREIRA, 2010).

Dentro do contexto ambiental, Manzini e Vezzoli (2002) definem PSS como sendo uma estratégia de inovação em que o foco do negócio de uma empresa "migra do projeto (e comercialização) de produtos físicos para projeto (e comercialização) de um sistema de bens e serviços" que atuam de forma conjunta para satisfazerem uma demanda específica do cliente.

O Sistema Produto-Serviço é uma das ferramentas do design para a sustentabilidade e possui como objetivo reduzir o conteúdo material por unidade de satisfação. Para Manzini e Vezzoli (2002) PSS tem como característica a mudança de enfoque de produtos físicos para um sistema integrado que visa oferecer soluções para os consumidores.

Em termos ambientais, segundo Borchard, Sellitto e Pereira (2010), em muitos casos não será mais necessário que cada consumidor adquira o produto físico, mas o uso do bem, visto que, uma das possíveis contribuições do PSS é a maximização do uso dos recursos.

Tal aspecto pode ser considerado em casos de PSS tanto pelo ponto de vista dos equipamentos que são utilizados para a prestação dos serviços, como a partir do ponto de vista dos insumos utilizados no processamento do produto ou serviço; como exemplo, empresa como a Xerox, que oferece soluções por meio do aluguel ou compartilhamento de impressoras.

McAloone e Andreasen (2004, p. 4) consideram relevante identificar em um PSS as seguintes características:(i) no tempo, as fases ao longo do ciclo de vida; (ii) no âmbito do artefato, os múltiplos e inter-relacionados subsistemas, tanto físicos como gerenciais (manutenção, reformas, reposições, 
desempenho); (iii) quanto ao valor, os diversos interessados na utilização e na geração de benefícios e ônus; e (iv) no campo social, identificar atitudes e responsabilidades com o sistema ambiental resultante.

Modelos de PSS foram categorizados de acordo com diferentes tipos de gestão e solução, assim autores como Azarenko et al. (2009), Rese, Strotmann e Karger (2009) e Yang et al. (2009) apresentam três categorias de PSS: (i) productorientedservice; (ii) use-orientedservice e (iii) result-orientedservice. Cada uma dessas categorias tem particularidades com relação aos aspectos econômicos e ambientais. Tukker (2004) desdobrou as mesmas, apresentando oito tipos de PSS a seguir pelo quadro descrito.

\section{Quadro 1- Categorias de PSS}

\begin{tabular}{|c|c|c|}
\hline $\begin{array}{l}\text { Categorias - } \\
\text { Azarenk et al. } \\
\text { (2009), Reseet al. } \\
\text { (2009.a) e Yang et } \\
\text { al. (2009) }\end{array}$ & $\begin{array}{c}\text { Categorias - Tukker } \\
(2004)\end{array}$ & Soluções \\
\hline \multirow[t]{2}{*}{$\begin{array}{l}\text { Product-oriented- } \\
\text { service }\end{array}$} & $\begin{array}{l}\text { Produto relaciona- } \\
\text { do ao serviço }\end{array}$ & $\begin{array}{l}\text { Venda do produto físico com serviço } \\
\text { oferta de serviços. (ex: contrato de ma- } \\
\text { nutenção). }\end{array}$ \\
\hline & $\begin{array}{l}\text { Assessoria e con- } \\
\text { sultoria }\end{array}$ & $\begin{array}{l}\text { Provedor de serviços fornece assessoria } \\
\text { para a obtenção de uso mais eficiente } \\
\text { (ex: otimizar a logística; prover treina- } \\
\text { mento organizacional para o uso do } \\
\text { produto). }\end{array}$ \\
\hline \multirow[t]{3}{*}{$\begin{array}{l}\text { Use-orientedser- } \\
\text { vice }\end{array}$} & $\begin{array}{l}\text { Leasing de produ- } \\
\text { tos }\end{array}$ & $\begin{array}{l}\text { Um provedor de serviços mantém o } \\
\text { direito de propriedade do bem e define } \\
\text { as condições de uso do mesmo, sendo, } \\
\text { muitas vezes, responsável pela manu- } \\
\text { tenção, reparo, controle. Nesse caso, há } \\
\text { o pagamento regular de uma taxa para } \\
\text { o uso }\end{array}$ \\
\hline & $\begin{array}{l}\text { Aluguel de produ- } \\
\text { tos ou comparti- } \\
\text { Ihamento }\end{array}$ & $\begin{array}{l}\text { O usuário não tem acesso ilimitado e } \\
\text { individual ao produto físico; o mesmo } \\
\text { produto pode ser utilizado seqüencial- } \\
\text { mente por diferentes usuários. }\end{array}$ \\
\hline & Productpooling & $\begin{array}{l}\text { Similar ao aluguel de produtos ou com- } \\
\text { partilhamento, porém há um simultâ- } \\
\text { neo uso do produto físico por diversos } \\
\text { usuários. }\end{array}$ \\
\hline
\end{tabular}




\begin{tabular}{|l|l|l|}
\hline $\begin{array}{l}\text { Result-oriented- } \\
\text { service. }\end{array}$ & $\begin{array}{l}\text { Atividade de ge- } \\
\text { renciamento e ter- } \\
\text { ceirização }\end{array}$ & $\begin{array}{l}\text { Parte das atividades de uma empresa é } \\
\text { terceirizada para outra empresa, sendo } \\
\text { os terceiros medidos através de indica- } \\
\text { dores de desempenho. }\end{array}$ \\
\hline $\begin{array}{l}\text { Pagamento por } \\
\text { unidade de serviço }\end{array}$ & $\begin{array}{l}\text { O usuário não compra o produto físico } \\
\text { e sim um resultado desse produto de } \\
\text { acordo com o nível de serviço (exem- } \\
\text { plo: pagamento de cópias impressas ao } \\
\text { provedor de serviços de impressão). }\end{array}$ \\
\hline nesultados funcio- & $\begin{array}{l}\text { O provedor de serviços acorda com } \\
\text { o cliente o resultado a ser entregue } \\
\text { (exemplo: oferecer ambiente termica- } \\
\text { mente agradável no lugar de comercia- } \\
\text { lizar o equipamento de ar condiciona- } \\
\text { do). }\end{array}$ \\
\hline
\end{tabular}

Fonte: Adaptado de Borchard, Sellitto e Pereira (2010).

De acordo Mont (2002) é considerado em pesquisas recentes o contexto ambiental em casos de PSS, no que se referem à mensuração dos benefícios ambientais, incluindo o reprocessamento, uso de produtos e componentes.

A partir do quadro acima é possível estabelecer uma relação entre as categorias de PSS e modelos de servitização com foco no recondicionamento de produtos, assim destaca-se a categoria Result-orientedservice, onde o usuário paga por unidade de serviço. Esse tipo de serviço está associado a exemplos de serviço como: lavanderias self-service, copiadoras e incluindo empresas como as que prestam serviço de renovação de produtos.

\section{Design e a Sustentabilidade}

O design para sustentabilidade vista sob o aspecto ambiental é tratado a partir de diferentes abordagens; uma delas, a do ecodesign clássico como descritas por Papanek e Kazazian que leva em conta o impacto ambiental durante a fase de produção de bens de consumo, considerando o uso de fonte renováveis, processos produtivos limpos e descarte ambientalmente correto.

Nesse contexto abordagens mais recentes levam em conta não somente a forma de produção, mas considera todo o ciclo de vida dos materiais nas fases de distribuição, uso e eliminação (MANZINI; VEZZOLI, 2002).

Pesquisadores do norte europeu estão denominando de design para comportamento sustentável a partir do projeto de produtos e/ou serviços centrados na fase de consumo (BHAMRA; LILLEY; TANG, 2011). 
Hansen e Andreasen (2002) defendem que os designers precisam lidar com dois aspectos de propostas de valor durante o projeto, um deles é denominado como "ideawith", a outra "idea in". A "ideawith" é a proposta de valor na construção do produto (material, tecnologia, infraestrutura, etc), enquanto que a "idea in" é a vantagem (em relação às necessidades e valores de um cliente).

Considerando a sustentabilidade como valor, poderíamos fazer a seguinte distinção: de um lado a sustentabilidade vista na perspectiva do produto, e de outro na perspectiva do usuário que nesse caso levando em conta a sua relação (comportamento) com o produto como parte importante para a sustentabilidade.

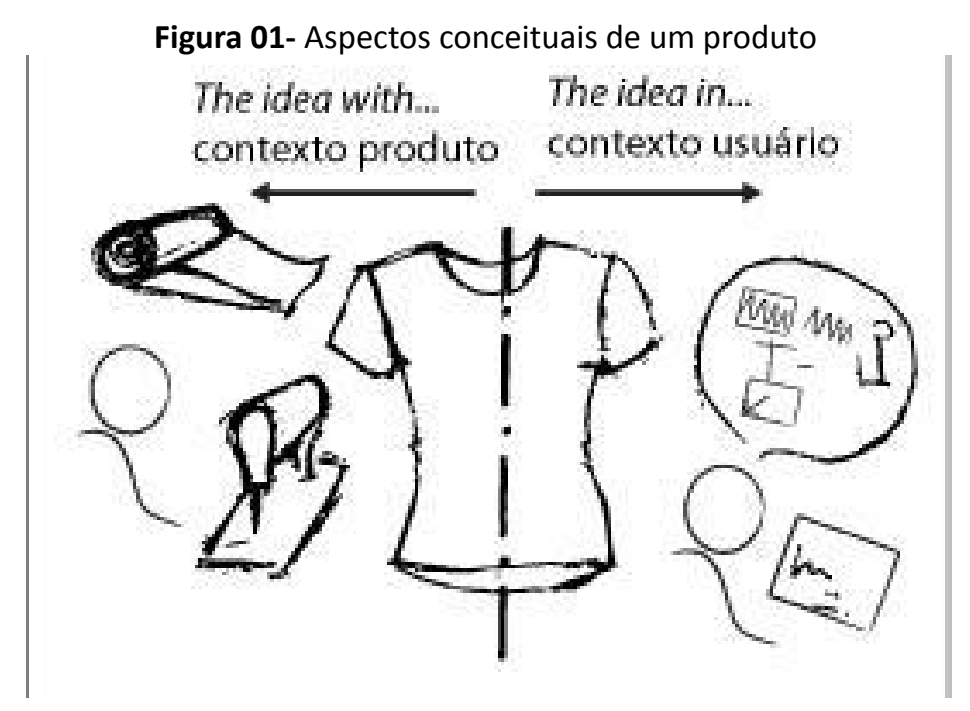

Fonte: Adaptada de Hansen e Andreasen (2002).

O Design nesse sentido passa de uma visão com enfoque nos meios de produção, para uma visão aberta e sistêmica, levando em conta os envolvidos tanto como o processo produtivo como com a fase de consumo do produto.

Levando em conta o impacto ambiental do produto vestuário, a partir da fase de uso, modelos de serviço como lavanderias self-service permitem uma maximização dos recursos, se comparados a uma lavagem doméstica, assim aspectos como; as proporções de água e detergentes, e melhores condições de controle e tratamento de resíduos tóxicos, podem resultar num modo de produção mais limpa.

Outros aspectos estão atrelados a forma de uso e seu impacto ambiental, e com relação ao vestuário, que está diretamente ligado ao comportamento.

Segundo Anicet e Rüthschilling (2013) a forma que o usuário busca pela 
durabilidade no vestuário está atrelado aos cuidados com a manutenção da roupa e isso abrange a conscientização na lavagem, como o uso de energia, de água e de produtos químicos, assim como também a forma de secagem e passadoria.

De acordo com uma pesquisa realizada por Laitala e Boks (2012), os resultados mostram que a fase de uso do produto pode ser a fase de maior consumo de energia de todo percurso do ciclo de vida (lifecycle) e, dependendo da fonte de energia, pode ser também a mais poluente (LAITALA; BOKS, 2012).

Autores como (BHAMRA; LILLEY; TANG, 2011) consideram que o consumo envolva várias etapas que interferem no impacto ambiental, levando em conta as tomadas de decisão do usuário sobre a escolha, compra e descarte; e rotinas e comportamentos de uso e modificação do produto de forma concreta e/ou simbólica. Esses fatores podem ajudar a identificar oportunidades de inserção de novas abordagens no consumo visando aumentar a sustentabilidade.

\section{O uso do Vestuário e a Sustentabilidade}

Tomando como análise de um produto de vestuário, relacionemos a pesquisa realizada por Laitala e Boks (2012) com base em um estudo do comportamento de mulheres norueguesas de 30-40 anos, dentro deste contexto o estudo mostra que o tempo de vida das roupas, é em média de sete anos, incluindo o tempo que a roupa fica estocada no guarda roupa. De acordo com esta pesquisa é possível perceber que o desuso acontece muito antes do tempo do final de seu ciclo de vida, que acontecem em decorrência de fatores ligados: (i) novas necessidades de consumo, (ii) mudança de tamanho, (iii) aspectos funcionais, técnico ou de qualidade; como também (iiii) fatores psicológicos como a compra por impulso, e o desuso motivado por preservação (apego).

De acordo com os fatores apresentados por Laitala e Boks (2012) é possível fazer a seguinte relação de um lado o desgaste material/funcional, e de outros fatores ligados a aspectos psicológicos, que estariam associados ao desgaste simbólico, onde o motivo do desuso está ligado ao fato de o usuário sentir-se apegado a roupa e por isso não compartilha, doa, ou mesmo vende, gerando estoque de roupas no guarda-roupa.

Também estão ligados ao desgaste simbólico ofato de o usuário estar cansado do produto, então ele busca por algo "novo", ou acaba comprando por impulso, que nesse sentido essa motivação de consumo gera consequentemente o descarte de um outro produto ou desuso. A motivação pela compra de algo 
novo, e muitas vezes motivado pelo próprio sistema da moda que nesse caso influência as decisões de compra, uso, descarte; permeando assim o que na figura corresponde ao desgaste simbólico.

Figura 02- Relação Uso/Descarte-Desuso

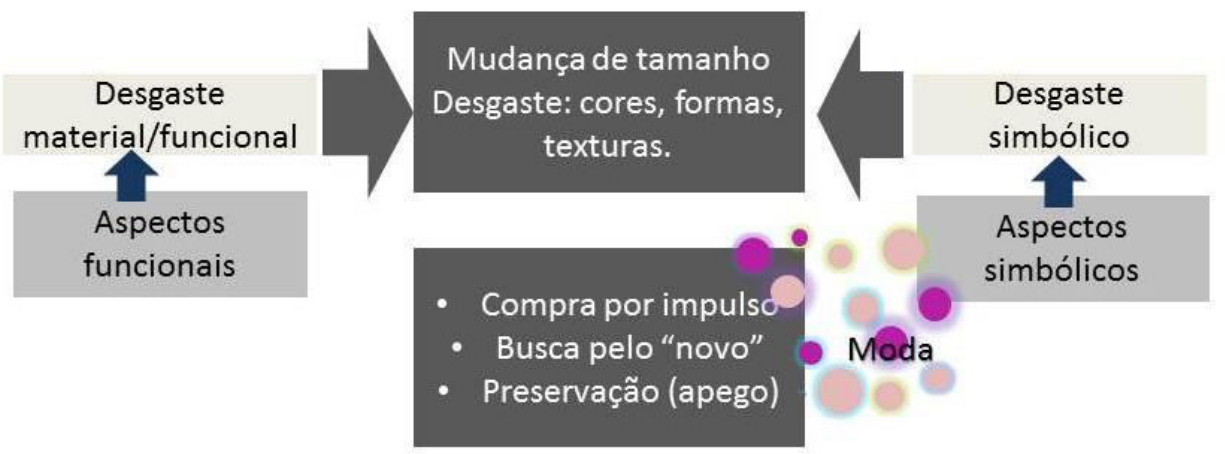

Fonte: Elaborado pelos autores, 2013.

Segundo Fletcher (2011) produtos de consumo e, por conseguinte a moda reflete valores mais amplos da sociedade - um padrão ou modo de vida aceito - e, portanto nutrem nossa necessidade de pertencimento. Neste sentido, a moda constitui para o vestuário incluindo roupas e acessórios seu campo de significação mais amplo, assim o tempo de uso de uma roupa é determinado pelo que o sistema da moda institui como legítimo. A moda da mesma forma que atribui qualidades simbólicas ao produto é também responsável pela obsolescência programada, onde o tempo de vida de uso do produto termina enquanto ainda se mantém sua qualidade técnica e funcional.

\section{Análise de uma empresa que recondiciona Vestuário e o PSS}

Considerando o design para comportamento sustentável a partir do projeto de produtos e/ou serviços centrados na fase de consumo propostos por (BHAMRA; LILLEY; TANG, 2011) e modelos de PSS propostos por Manzini e Vezzoli (2002) onde considera o PSS durante a fase de uso e eliminação. Este estudo pretende analisar a relação do serviço prestado por uma empresa que recondiciona produtos do vestuário e a sustentabilidade e como um modelo em PSS poderia contribuir com a prolongação do tempo de uso do produtovestuário.

Para que se faça uma análise é necessário que se identifique na organização qual o produto e/ou serviço oferecido. Assim foram identificados com base numa pesquisa documental os seguintes serviços oferecidos pela empresa. 
Quadro 2- Empresa x categorias de PSS

\begin{tabular}{|c|c|c|}
\hline Estudo de caso & Categorias de PSS & Soluc̣ões - Serviço \\
\hline $\begin{array}{l}\text { Empresa de recondiciona- } \\
\text { mento de roupas }\end{array}$ & $\begin{array}{l}\text { Result-orientedservice- } \\
\text { Pagamento por unidade } \\
\text { de serviço. }\end{array}$ & $\begin{array}{ll}\bigotimes & \text { Tingimento; } \\
\bigotimes & \text { Costura e reforma } \\
& \text { sob medida; } \\
\bigotimes & \text { Renovação de } \\
& \text { couro; } \\
\bigotimes & \text { Lavanderia. }\end{array}$ \\
\hline
\end{tabular}

Fonte: Elaborado pelos autores, 2013

De acordo com o caso estudado o processo de tingimento e lavanderia industrial é realizado em empresas terceirizadas, e a costura e reformas são feitas nas unidades franquiadas.

A definição da customização (modificação do vestuário) é feito de acordo com a necessidade do cliente modificando o produto por meio de ornamentações e pequenas modificações.

De acordo a figura abaixo (3) podemos compreender o sistema produtoserviço a partir dos insumos de entrada (input) que e tratado no gráfico como os artefatos usados (roupas) que são entregues pelo cliente para o recondicionamento para que seja processado por meio de tingimento, lavagem, e quando necessário de costura. O sistema representa como saída (output) o produto é renovado/recondicionado.

Figura 3- Sistema de uma empresa que recondiciona roupas

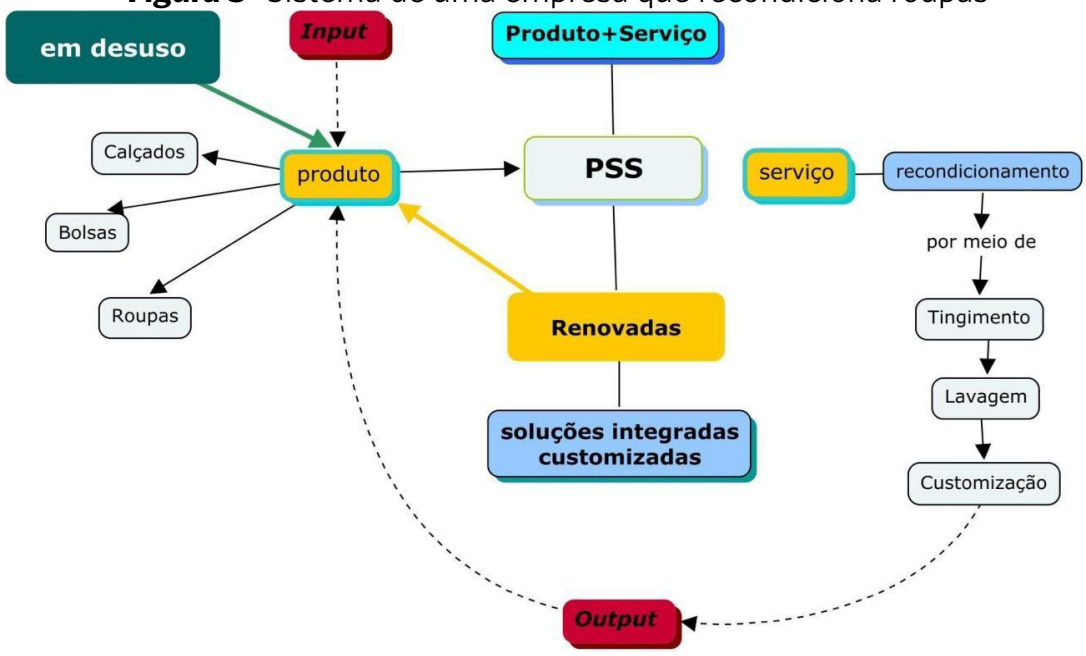

Fonte: Elaborado pelos autores, 2013

\section{Modelo em PSS}

Relacionando o ciclo de vida de um produto com a sustentabilidade, 
consideremos os fatores apontados por Laitala e Boks (2012): circunstanciais, funcionais, técnica ou de qualidade, psicológica.

Seu ciclo de vida é variável, sendo que de acordo com os autores o tempo de vida de uma peça de malha pode chegar a sete anos; porém o fator psicológico, que está associado ao desuso em função da busca por algo novo, neste caso pode ser associado à moda, que promove o descarte de acordo com o ciclo das tendências de moda. Tempo muito inferior ao seu tempo de vida útil.

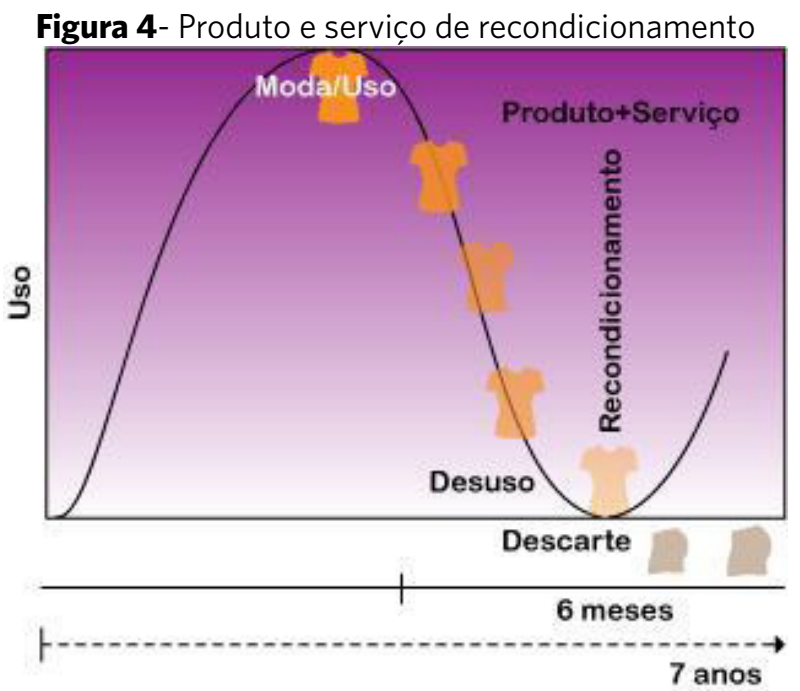

Fonte: Elaborado pelos autores, 2013

Um produto referenciado nas tendências de moda sofre uma maior oscilação entre o tempo de lançamento do produto e o seu desuso. Segundo Treptow (2013) a moda segue a seguinte trajetória:

\footnotetext{
MODA $=$ Lançamento $>$ Consenso $>$ Consumo ampliado $>$ Massificação $>$ Desgaste
}

Neste sentido, de acordo com o diagrama acima o uso intensivo se localiza no ápice do gráfico, correspondendo ao período do consenso e massificação, onde sua queda inicia-se logo em seguida, chegando rapidamente ao desgaste que no gráfico está relacionado com o desuso do produto. Este percurso se relaciona com o tempo de lançamento das tendências de moda que é de aproximadamente seis meses.

De acordo com o modelo de serviço representado pelo diagrama (fig.4), o processo de recondicionamento de roupas, ocorre num momento em que o produto poderia ser colocado em desuso ou descarte, assim considera-se uma intervenção capaz de prolongar o tempo de vida de um produto (vestuário). 
Processos que mudam os aspectos formais do produto renovando a cor por meio de tingimentos e lavagens, bem como costuras que recondicionam aspectos técnicos funcionais. Ainda é possível agregar na roupa elementos simbólicos, que neste sentido recondiciona o produto não somente renovando as suas qualidades técnicas-funcionais, mas renovando o seu sentido simbólico.

O produto que cairia em desuso ou até estaria sendo descartado, teria seu ciclo de vida prolongado.

\section{RESULTADOS}

Segundo o diagrama (fig.5) representa como uma ação estratégica de gestão de design poderia contribuir atuando de forma intensiva no recondicionamento do produto.

Além de levar em conta as ações que fazem parte do processo, o modelo se aplicaria a partir do possível desdobramento dos processos, onde a participação do design de moda teria um papel fundamental, atuando tanto a fase projetual, como durante a fase de produção (recondicionamento do produto).

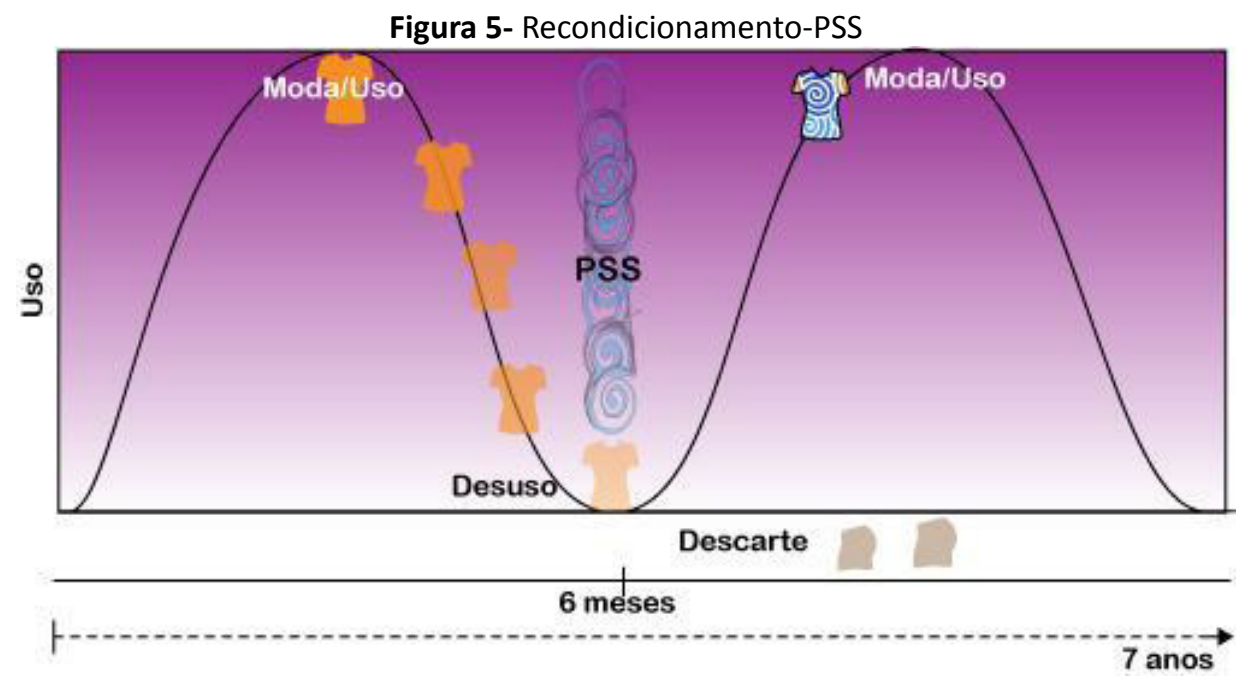

Fonte: Elaborada pelos autores, 2013

Assim a moda como responsável pelo descarte prematuro em função de seu sistema de obsolescência programada, atuaria em um sistema de PSS contribuindo com a renovação estética e simbólica do produto.

Processos que já fazem parte do serviço oferecido pela empresa, como o tingimento e lavagem, e, por conseguinte processos de descostura, corte e 
costura. No modelo proposto estaria sendo utilizado de forma a aproveitar os recursos técnicos e materiais, bem como uso de habilidades, competências que fazem parte do capital humano da empresa.

O design de moda atuaria neste sistema considerando o designer de moda como agente nesse processo, pelo uso de suas competências, bem como a moda como informação e direcionamento para recondicionamento de produtos.

Contudo possibilitaria um ganho em valor atuando de forma a renovar por meio da recomposição e inserção de elementos como a ornamentação, e num nível mais complexo envolvendo a reconstrução do modelo, que assim estariam dando a possibilidade de recombinar com outros materiais descartados.

Figura 06- Modelo antes e depois do recondicionamento

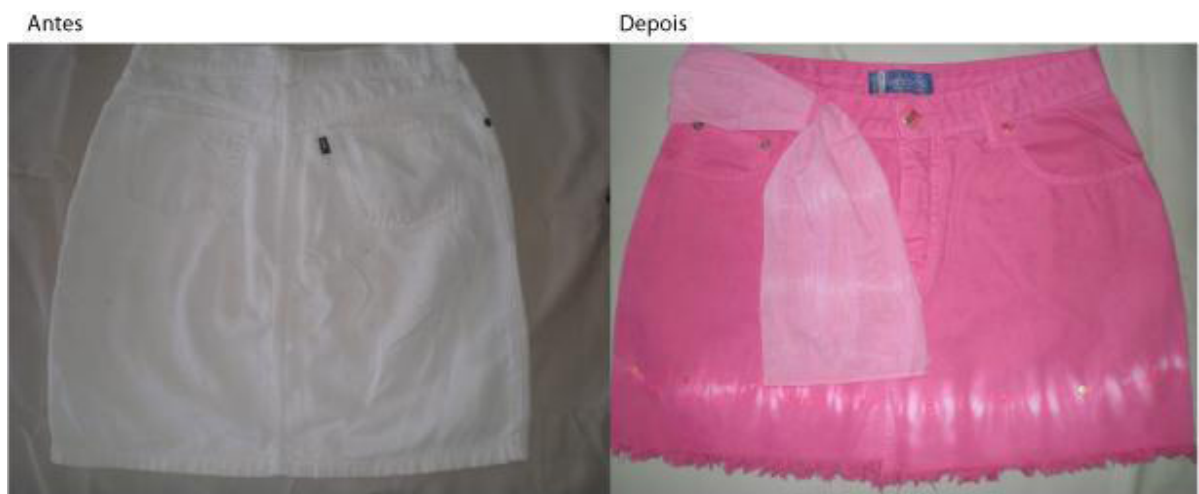

Fonte: Elaborado pelos autores, 2013

\section{CONCLUSÃO}

De acordo com o levantamento bibliográfico, um dos principais ganhos de um PSS é a sustentabilidade, porém empresas que oferecem soluções em serviço nem sempre aplicam a sustentabilidade em níveis estratégicos, sendo tratado como uma ação paralela à inovação da empresa.

Neste estudo valendo-se de conceitos de PSS, foi possível fazer uma relação entre uma empresa que oferece soluções de recondicionamento de roupas e modelos de PSS e assim identificar práticas sustentáveis. A gestão de design com base na representação de gráficos possibilitou a identificação da empresa como um sistema e propor ações de design em parceria com áreas inter-relacionadas como o design de moda, possibilitando inovações tanto pelo ponto de vista da solução oferecida, representado pelo produto renovado a partir de sua qualidade simbólica, como um prolongamento no seu tempo de 
vida útil.

De acordo com Borchadt, Sellitto e Pereira (2010) apesar de modelos de PSS tratarem amplamente de conceitos e tipologias, muito ainda pode ser feito a partir da identificação de elementos preponderantes no projeto de PSS. A gestão de design a partir de uma abordagem sistêmica é capaz não somente de identificar em um determinado contexto seus elementos e suas relações como possibilita contribuir com o reconhecimento dos valores de uma empresa.

Assim além de identificar as competências organizacionais no que se refere aos recursos técnicos e de infraestrutura, é também possível identificar valores como a sustentabilidade, que a partir do seu reconhecimento possa fazer parte da cultura organizacional, comoem um nível ampliado contribuir com a conscientização na fase de consumo.

\section{REFERÊNCIAS}

ANICET, A.; RÜTHSCHILLING, E. Moda e consumo sustentável. In: COLÓQUIO DE MODA, 8., 2013, Rio de Janeiro. Anais eletrônico... Rio de janeiro: SENAI-CETIQT, 2013. Disponível em: <http://www. coloquiomoda.com.br/anais/>. Acesso em: 25 abr. 2013.

AZARENKO, A. et al. Technical product-service systems: some implications for themachine tool industry. Journal of Manufacturing Technology Management, London, v. 20, n. 5, p. 700-722, 2009.

BHAMRA, T.; LILLEY, D.; TANG, T. Design for Sustainable Behaviour: using products to change consumer behavior. The design Journal, London, v. 14, n. 4, p.427-445, 2011.

BORCHARDT, M.; SELLITTO, M. A.M.; PEREIRA, G.M. Sistemas produto-serviço : referencial teórico e direções para futuras pesquisas. Revista Produção Online, Florianópolis, v.10, n. 4, p.837-860, 2010.

FLETCHER, K. Moda \& sustentabilidade: design para mudança. São Paulo: SENAC-SP, 2011.

HANSEN, C.T.; ANDREASEN, M.M. Two approaches tosyn thesis based on domain theory. London: Springer-Verlag, 2002.

KAZAZIAN, t. Haverá a idade das coisas leves: design e desenvolvimento sustentável. São Paulo: Ed. SENAC, 2005. 
LAITALA, K.; BOKS, C. Sustainable clothing design: use matters. Journal of Design Research, Genèva, v.10, n. 1-2, p.121-139, 2012. Disponível em:<http://inderscience.metapress.com/ content/ w81206135wv62684/>. Acesso em: 12 mar. 2013.

MANZINI, E; VEZZOLI, C. Product-Service Systems and Sustainability. Paris: UNEP, Division of Technology Industry and Economics. 2003.

O Desenvolvimento de Produtos Sustentáveis: os requisitos ambientais dos produtos industriais. São Paulo: Edusp, 2002.

MCALOONE, T.; ANDREASEN, M. Design for utility, sustainability and societal virtues: Developing Product Service Systems. In: INTERNATIONAL DESIGN CONFERENCE : DESIGN, 2004, Dubrovnik. Proceedings... Dubrovnik, 2004.

MONT, O. K. Clarifying the concept to product-service system. Journal of Cleaner Production, Amsterdam, v. 10, p. 237-245, 2002.

PAPANECK, V. Arquitetura e Design. Lisboa: Edições 70, 1995.

RESE, M.; STROTMANN, W.; KARGER, M. Which industrial product service system fitsbest? Evaluating flexible alternatives based on customers' preference drivers. Journal of Manufacturing Technology Management, London, v. 20, n. 5, p. 640-653, 2009.

SPRING, M.; ARAÚJO, L. Service, services and products: rethinking operations strategy. Internacional Journal of Operations \& Production Management, Bradford, v. 29, n. 5, p. 444-467, 2009.

TREPTOW, D. Inventando Moda: planejamento de coleção. 5. ed. São Paulo, 2013.

TUKKER, A. Eight typesof product-service system: eight ways to sustainability? Experiences from SusProNet. Business Strategy and the Environment, v. 13, n. 4, p. 246-260, 2004.

YANG, X.; MOORE, P.; PU, J.; WONG, C. A practical methodology for realizing product service systems for consumer products. Computers $\&$ Industrial Engineering, New York, v. 56, p. 224-235, 2009. 